\title{
Do caregiver profiles predict the use of dementia care services? Findings from the Actifcare study
}

Citation for published version (APA):

Kerpershoek, L., Woods, B., Wolfs, C., Verhey, F., Jelley, H., Bieber, A., Stephan, A., Michelet, M., Selbaek, G., Handels, R., Wimo, A., Hopper, L., Irving, K., Marques, M. J., Goncalves-Pereira, M., Portolani, E., Zanetti, O., de Vugt, M., Meyer, G., ... ActifCare Consortium (2020). Do caregiver profiles predict the use of dementia care services? Findings from the Actifcare study. Aging \& Mental Health, 24(2), 272-279. https://doi.org/10.1080/13607863.2018.1544215

Document status and date:

Published: 01/02/2020

DOI:

10.1080/13607863.2018.1544215

Document Version:

Publisher's PDF, also known as Version of record

Document license:

Taverne

Please check the document version of this publication:

- A submitted manuscript is the version of the article upon submission and before peer-review. There can be important differences between the submitted version and the official published version of record.

People interested in the research are advised to contact the author for the final version of the publication, or visit the DOI to the publisher's website.

- The final author version and the galley proof are versions of the publication after peer review.

- The final published version features the final layout of the paper including the volume, issue and page numbers.

Link to publication

\footnotetext{
General rights rights.

- You may freely distribute the URL identifying the publication in the public portal. please follow below link for the End User Agreement:

www.umlib.nl/taverne-license

Take down policy

If you believe that this document breaches copyright please contact us at:

repository@maastrichtuniversity.nl

providing details and we will investigate your claim.
}

Copyright and moral rights for the publications made accessible in the public portal are retained by the authors and/or other copyright owners and it is a condition of accessing publications that users recognise and abide by the legal requirements associated with these

- Users may download and print one copy of any publication from the public portal for the purpose of private study or research.

- You may not further distribute the material or use it for any profit-making activity or commercial gain

If the publication is distributed under the terms of Article $25 \mathrm{fa}$ of the Dutch Copyright Act, indicated by the "Taverne" license above, 


\title{
Do caregiver profiles predict the use of dementia care services? Findings from the Actifcare study
}

\author{
Liselot Kerpershoek, Bob Woods, Claire Wolfs, Frans Verhey, Hannah \\ Jelley, Anja Bieber, Astrid Stephan, Mona Michelet, Geir Selbaek, Ron \\ Handels, Anders Wimo, Louise Hopper, Kate Irving, Maria J. Marques, \\ Manuel Gonçalves-Pereira, Elisa Portolani, Orazio Zanetti, Marjolein de Vugt \\ \& and the Actifcare Consortium
}

To cite this article: Liselot Kerpershoek, Bob Woods, Claire Wolfs, Frans Verhey, Hannah Jelley, Anja Bieber, Astrid Stephan, Mona Michelet, Geir Selbaek, Ron Handels, Anders Wimo, Louise Hopper, Kate Irving, Maria J. Marques, Manuel Gonçalves-Pereira, Elisa Portolani, Orazio Zanetti, Marjolein de Vugt \& and the Actifcare Consortium (2020) Do caregiver profiles predict the use of dementia care services? Findings from the Actifcare study, Aging \& Mental Health, 24:2, 272-279, DOI: $10.1080 / 13607863.2018 .1544215$

To link to this article: https://doi.org/10.1080/13607863.2018.1544215

Published online: 06 Dec 2018.

山 Article views: 406

View Crossmark data ¿
Submit your article to this journal \lceil
View related articles $₫$

Citing articles: 1 View citing articles $\widetilde{\jmath}$ 


\title{
Do caregiver profiles predict the use of dementia care services? Findings from the Actifcare study
}

\author{
Liselot Kerpershoek ${ }^{a, b}$, Bob Woods ${ }^{c}$, Claire Wolfs ${ }^{a, b}$, Frans Verhey ${ }^{a, b}$, Hannah Jelley ${ }^{c}$, Anja Bieber ${ }^{d}$, Astrid \\ Stephan ${ }^{d}$, Mona Michelet ${ }^{\mathrm{e},}$, Geir Selbaek ${ }^{\mathrm{e}, \mathrm{f}, \mathrm{g}}$, Ron Handels ${ }^{\mathrm{a}, \mathrm{b}, \mathrm{h}}$ (D), Anders Wimo ${ }^{\mathrm{h}}$, Louise Hopperi, Kate \\ Irvingi, Maria J. Marques ${ }^{j}$, Manuel Gonçalves-Pereira ${ }^{j}$ (D), Elisa Portolani ${ }^{k}$, Orazio Zanetti ${ }^{k}$, Marjolein de \\ Vugt $^{\mathrm{a}, \mathrm{b}}$ (D) and the Actifcare Consortium
}

\begin{abstract}
${ }^{a}$ Alzheimer Centre Limburg, Maastricht, Netherlands; ${ }^{b}$ Maastricht University, Maastricht, Netherlands; 'Bangor University, Gwynedd, UK; ${ }^{\mathrm{d}}$ Martin-Luther University Halle-Wittenberg, Halle, Germany; ${ }^{\mathrm{e}}$ Norwegian National Advisory Unit on Ageing and Health, Vestfold Hospital, Tonsberg, Norway; ${ }^{f}$ Faculty of Medicine, University of Oslo, Oslo, Norway; ${ }^{9}$ Centre for Old Age Psychiatry Research, Innlandet

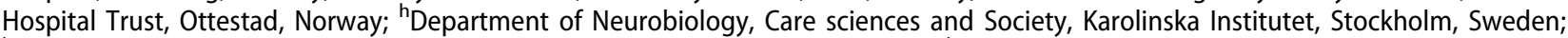
iSchool of Nursing and Human Sciences, Dublin City University, Dublin, Ireland; 'Nova Medical School, Faculdade de Ciências Médicas, Universidade Nova de Lisboa, CEDOC, Lisboa, Portugal; 'Alzheimer's Research Unit-Memory Clinic, IRCCS “Centro S. Giovanni di Dio, Brescia, Italy
\end{abstract}

\begin{abstract}
Objectives: Previously developed dementia caregiver profiles defined by caregiver age and burden, have been associated with caregiver quality of life, depression and perseverance time. The current aim was to investigate whether these caregiver profiles could predict subsequent service use. In addition, non-personal (e.g. meals on wheels) and supportive services (e.g. Alzheimer café) in early dementia were investigated as predictors.

Methods: A total of 451 dyads of people with dementia and their informal caregivers from eight European countries were followed for one year. People were included if they did not use formal (personal) care but were expected to do so within 1 year. Logistic regression analyses were used with four clusters of service use as dependent variables (home social care, home personal care, day care and admission). The independent variables were caregiver profiles, and non-personal and supportive services at baseline.

Results: Caregiver profiles were significant predictors of service use; those experiencing high strain were more likely to use formal care. The use of low-intensity, less intrusive services at baseline significantly predicted the use of home personal care and admission at follow-up. The use of day care at follow-up was predicted by the baseline use of supportive services.

Conclusion: Caregiver profiles are valuable predictors for service use: this knowledge can aid professionals in ensuring optimal access to services, which is important for maintaining independence at home. In addition, the use of supportive and less intrusive, non-personal services in the early stages of dementia is to be advised.
\end{abstract}

ARTICLE HISTORY

Received 23 June 2018

Accepted 21 October 2018

\section{KEYWORDS}

Dementia; informal

caregiver; caregiver profiles; service use

\section{Introduction}

Many countries pursue health care policies aimed at enabling people with dementia to live at home for as long as possible, while being offered a wide range of community and social care services. The majority of people with dementia currently receive care and support from informal caregivers (Stockwell-Smith, Kellett, \& Moyle, 2010). They are often spouses or partners who are of a similar age and who often have health problems themselves. At some point in the disease, when needs of the person with dementia can no longer be met with informal care alone, formal care services such as day care or personal care become necessary (Toseland, McCallion, Gerber, \& Banks, 2002): a combination of these two types of care occurs more often when the amount of needs is higher (Litwin \& Attias-Donfut, 2009). Yet, previous studies indicate that formal dementia services are not being accessed as much as needed (Brodaty, Thomson, Thompson, \& Fine, 2005; Phillipson, Jones, \& Magee, 2014; Robinson, Buckwalter, \&
Reed, 2005), and are used less frequently compared to people requiring care due to other conditions (Vecchio, Fitzgerald, Radford, \& Fisher, 2016). There is a tendency for people with dementia to use medical services more often than community services (Weber, Pirraglia, \& Kunik, 2011) while at the same time expressing the need and preference for community and social services (Jelley et al., 2018; Kerpershoek et al., 2018). Health and social care policy tends to encourage people with dementia to live at home for as long as possible, but this can only be realized if informal care is supplemented with appropriate formal care. It is therefore important for governments to understand the reasons behind the non-use of formal care services and the associated social and economic consequences of this non-use (Toseland et al., 2002). So far, reported reasons for the non-use of care services include refusal of the person with dementia to receive care, a lack of knowledge about available services, services not being of the right type, and the consideration that care is not yet necessary (Brodaty et al., 2005; Phillipson et al., 2014; Stockwell-Smith 
et al., 2010). In addition, stigma, norms about being responsible for caregiving as a family, and negative experiences with previous health care services were found to play a role in non-use (Werner, Goldstein, Karpas, Chan, \& Lai, 2014). Recent years have seen the development of a range of services that offer support to people with dementia and caregivers, such as Alzheimer cafes, support groups and befriending services. It is unclear whether these supportive services help to break down some of the barriers to more intensive service use noted: previous qualitative Actifcare results do indicate that this is the case (Kerpershoek et al., 2018). The Actifcare study was a longitudinal cohort study in which access to formal care and experiences with formal care have been investigated. A group of 451 people with dementia and their primary informal carers were followed for one year about amongst others service use, needs and quality of life. (Kerpershoek et al., 2016).

When considering care (non)-use, there seems to be a complex interplay between factors related to the person with dementia and to the informal caregiver (Janssen et al., 2017). In a previous article based on the Actifcare baseline data (Janssen et al., 2017) five different caregiver profiles were established (Older Low Strain, Older Intermediate Strain, Older High Strain, Younger Low Strain, Younger High Strain) following a latent class analysis. A table with detailed information concerning the variables compromising these profiles is presented in the Appendix. These profiles included characteristics of the person with dementia and the informal caregiver, in an attempt to summarize the complex interaction between them. Subjective as well as objective burden was also included, where subjective burden is reflected by caregiving-related stress, and objective burden by more time spent with the person with dementia in a care-giving role (Wolfs et al., 2012). The higher strain profiles were characterized by lower cognitive functioning and more behavioural and psychological symptoms of the person with dementia. Interestingly, objective burden was highest in the Older Intermediate Strain group, but subjective burden was low: apparently these caregivers are more resilient and maintain good adjustment in dealing with a higher objective burden. The low strain profiles were associated with higher caregiver quality of life and a longer perseverance time (perceived ability to continue providing care at home), while the high strain profiles were associated with more depressive symptoms (Janssen et al., 2017). Since these caregiver profiles encompass a broad range of variables reflecting the complex interplay of several relevant factors of the person with dementia and informal caregivers, they may have utility in exploring the use of formal dementia care services. If caregiver profiles could predict service use, this may aid professionals in ensuring optimal access to services that are important for maintaining independence at home. The profiles were previously validated against baseline measures of caregiver quality of life, depression and perseverance time, so it would be informative to determine whether these other variables add to the prediction of later service use. Since reluctance of the person with dementia is one of the reasons cited for non-use of services (Brodaty et al., 2005), leading to potential conflict between caregiver and person with dementia, the quality of relationship between caregiver and person with dementia may also be relevant. It is also associated with caregiver stress (Quinn, Clare, \& Woods, 2009), and may add further to the prediction of later service use.

Accordingly, our research questions are as follows:

1. Can caregiver profiles in dementia predict the use of formal care services?

2. Do caregiver depression and anxiety, perseverance time, caregiver quality of life and relationship quality add to this prediction?

3. Does the use of non-personal services and supportive services at baseline predict the use of formal care services?

\section{Methods}

\section{Study design and participants}

The Actifcare study (ACcess to TImely Formal Care) investigated access to home- and community-based dementia care for people with mild to moderate dementia in eight European countries (The Netherlands, Germany, United Kingdom, Sweden, Norway, Ireland, Italy and Portugal). A wide range of research methods were used, such as literature reviews, focus groups, and expert interviews (Kerpershoek et al., 2016). In addition, a prospective oneyear cohort study was carried out in which people with dementia and their informal caregivers were followed and interviewed about topics including their needs, service use and quality of life. People with mild to moderate dementia according to DSM-IV-TR criteria were included, defined as having a CDR score of 1 or 2 (Morris, 1993) or an MMSE score lower than 25 (Folstein, Folstein, \& McHugh, 1975), together with an informal caregiver who was in contact with the person with dementia at least once a week. At baseline, the participants were not using formal care for personal care on account of their dementia. Formal care is defined within Actifcare as home nursing care, day care services, community or long-term medical care, nursing and social care structures that involve care from a paid worker. It does not include domestic home help, housekeepers, volunteers, support groups, transport services and meal programs. It was anticipated that participant dyads would start using formal care within one year, based on expert opinion. The complete design and in- and exclusion criteria of the Actifcare study have been described elsewhere, as well as information regarding ethical approval (Kerpershoek et al., 2016).

\section{Data collection and measurements}

Written informed consent was obtained separately from both the person with dementia and the informal caregiver according to the national procedure in each country, after a detailed explanation. Participants could withdraw their consent at any time during the study. Measurements were scheduled at baseline, and after six (FU1) and 12 (FU2) months. A variety of questionnaires were administered, in addition to the collection of demographic information and details on service use. More detailed information is presented elsewhere (Kerpershoek et al., 2016) 
Table 1. Composition of care clusters.

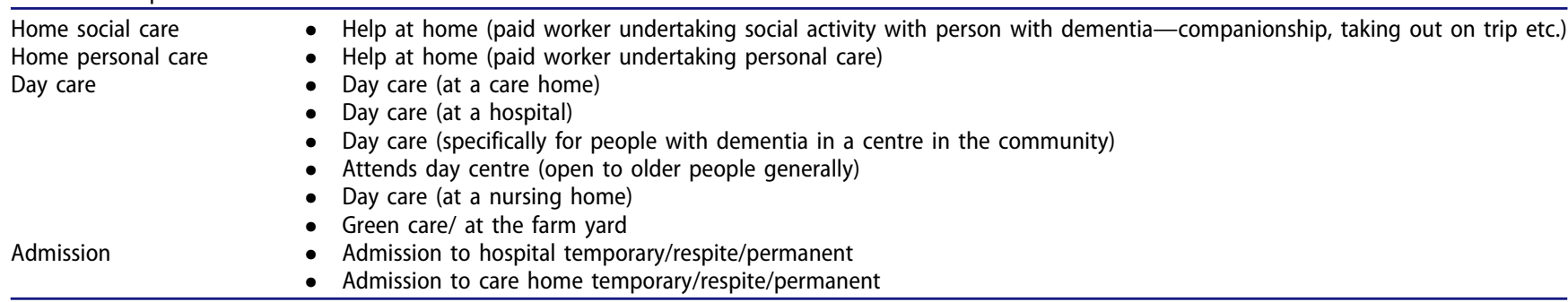

Pwd: person with dementia, IC: informal caregiver. Clusters defined by dichotomized scores: YES if one of the services within the care cluster is used. A care cluster was rated as 'yes' if the type of care was used at any of the two follow-ups.

\section{Measures for people with dementia}

Two widely used scales measured cognitive functioning: the Mini Mental State Examination (MMSE) (Folstein et al., 1975) and the researcher-rated Clinical Dementia Rating (Morris, 1993), of which the sum of boxes was used instead of the total score. Behavioural and psychological symptoms were assessed with the Neuropsychiatric Inventory Questionnaire, NPI-Q, in which the informal caregiver provided information on twelve neuropsychiatric symptoms of the person with dementia (Cummings et al., 1994). The NPI-Q has strong inter-rater reliability and moderate to strong convergent validity (De Medeiros et al., 2010).

\section{Measures for informal caregivers}

The extent of informal caregiving was measured with the Resource Utilization in Dementia scale (RUD), an instrument developed to reflect both formal and informal care use (Wimo et al., 2012), which has proven to be valid for this setting (A Wimo, Jonsson, \& Zbrozek, 2010). The number of hours spent on informal caregiving on personal and instrumental activities of daily living was collected. Stress related to caregiving was measured with the Relatives' Stress Scale (RSS) (Greene, Smith, Gardiner, \& Timbury, 1982), in which different patterns of distress are measured (Ulstein, Bruun, Wyller, \& Engedal, 2007). Perseverance time was measured with a single simple estimate of how long the informal caregiver considered he/she could continue in this way if the situation remained unchanged, with response options from 1 'less than one week' to 6 'more than two years'. Two scales were administered to investigate informal caregiver attributes: The Sense of Coherence Scale, 13 item version (SOC-13) and the Locus of Control Behaviour Scale (LOC). The SOC-13 indicates to what extent a person experiences life to be comprehensible, manageable and meaningful. It is not necessarily a stable trait as it has been described to increase with age (Antonovsky, 1993). This scale has proven to have good reliability, validity and is applicable across cultures (Eriksson \& Lindström, 2005). The LOC assesses whether someone perceives life events as being under personal control or as being attributable to external sources. The LOC has a good internal reliability and test-retest reliability (Craig, Franklin, \& Andrews, 1984). The Hospital Anxiety and Depression Scale (HADS) was used to measure depressive and anxious symptoms. The scale provides separate scores for depression and anxiety, where a score of zero indicates the absence, and a score of 21 indicates the presence of depressive or anxious symptoms (Zigmond \& Snaith, 1983). Results from a literature review showed that the HADS is able to assess symptom severity in a wide range of care settings (Bjelland, Dahl, Haug, \& Neckelmann, 2002). Caregiving related quality of life was measured with the Care-related Quality of life scale (CarerQol). The scale consists of 7 items, and a visual analogue scale (CarerQol-VAS) (Brouwer, van Exel, van Gorp, \& Redekop, 2006), and has shown to be feasible, valid and reliable (Hoefman, van Exel, Foets, \& Brouwer, 2011). The Positive Affect Index (PAI) was used to measure the person with dementia's and the caregiver's view of their relationship quality (Bengtson \& Schrader, 1982). It consists of five items, where a higher total score (range 5-30) indicates a better relationship quality.

\section{Caregiver profiles}

Caregiver profiles were established in a previous study (Janssen et al., 2017) with a latent class analysis, combining both baseline characteristics of the person with dementia and the informal caregiver. Five profiles were identified reflecting demographics of the informal caregiver, and the subjective and objective burden: younger caregivers experiencing low strain; younger caregivers experiencing high strain; older caregivers experiencing low strain; older caregivers experiencing high strain; and a cluster of older caregivers providing support to people with dementia with a high level of needs, but reporting comparatively low strain, described as the older intermediate strain group.

\section{Service use}

Information concerning the person with dementia's service use was collected with a checklist, constructed for the Actifcare study. It comprised 22-26 items to reflect different service constellations in each country, and was administered at each assessment (baseline, FU1, FU2). Checklist items in all countries were combined into four clusters: (1) help at home (social), (2) help at home (personal care), (3) day care, (4) admission to nursing or care home or longterm admission to hospital due to dementia (see Table 1 for details). The development process for these clusters has been described in more detail elsewhere (Kerpershoek et al., 2018). Next, scores were dichotomized for each cluster to reflect use at either of the two follow-up points. An extra cluster was created to describe non-personal services used at baseline that might facilitate access to formal care. This cluster includes meals on wheels, domestic services, help at home (social) and day care (without personal care). In addition, a cluster with supportive services was created, consisting of support groups, training sessions for the carer, individual or dyadic support and the Alzheimer café. 
Table 2. Sample characteristics $(\mathrm{N}=451)$ at baseline.

Person with dementia
Male ( $\mathrm{n}, \%$ )
Age (mean, [range], SD)
Education (mean years, SD)
Marital status ( $\mathrm{n}, \%)$
Married
Widowed
Single
Other
Living together with carer ( $\mathrm{n}, \%)$
Country

$207(46 \%)$

$77.4[47-92] 7.9$

$9.8,4.5$

$310(68 \%)$

$109(24 \%)$

$8(2 \%)$

$24(6 \%)$

$325(72 \%)$

$\mathrm{NL}(51) \mathrm{NO}(60)$

DE (52) SE (50)

UK (76) IT (53)

IE (43) PT (66)

Dementia type ( $\mathrm{n}, \%)$

Alzheimer's Disease

Vascular dementia

Mixed dementia

Lewy body dementia

Other/unknown

CDR sum of boxes (mean, [range], SD)

MMSE (mean, [SD])

NPI total score (mean, [SD])

Caregiver

Male (n, \%)

Age (mean, range, SD)

Range

Education (mean years, SD)

Marital status (n, \%)

Married

Widowed

Single

Other

Caregiver relation $(n, \%)$

Spouse

Child

Other

Caregiver profiles

Older High Strain ( $n, \%)$

Younger High Strain (n, \%)

Older Low Strain $(n, \%)$

Younger Low Strain ( $n, \%)$

Older Intermediate Strain ( $n, \%)$

PwD, person with dementia; CDR, clinical dementia rating scale.

$\mathrm{NL}$, The Netherlands; DE, Germany; UK, United Kingdom; IE, Ireland; NO Norway; SE, Sweden; IT, Italy; PT, Portugal.

\section{Statistical analyses}

Frequency distributions were calculated to describe service use and group characteristics at baseline. Separate automated logistic regressions were carried out for the four service use clusters, with a dichotomous dependent variable (service use yes/no) at FU1 and/or FU2. The five caregiver profiles were transformed to dummy codes, where the 'Old low strain' group was the reference group. In addition, CarerQol-sum and VAS, carer depression and anxiety, perseverance time on a continuous scale, and relationship quality were used as independent variables. Finally, dichotomous scores of personal and supportive service use at baseline were investigated as independent variables in separate logistics regression analyses.

\section{Results}

Group characteristics are displayed in Table 2. At baseline, 451 dyads were included in the study. At FU1 422 dyads still participated, and at FU2 339 dyads, which reflects a loss to follow up of $25 \%$ after one year. All those who completed at least FU1 were included in the regression analyses. The majority of the dyads were living together (72\%) and had a spousal relationship (60\%). Participants were reasonably evenly distributed across the five caregiver profiles, but the largest group was the Older Low Strain.

Table 3 displays the percentages of service use at baseline and at follow-up across the different caregiver profiles. The use of home personal care and admission to hospital or care home at baseline reflect care that was needed for reasons other than the person's dementia; the use of day care reflects use of a service not including personal care. Percentages of service use are the lowest in the low strain profiles.

Outcomes of the logistic regressions investigating the relationship between caregiver profiles and care use are presented in Table 4. In relation to home social care, chances of care use were higher for the intermediate and high strain profiles than for the low strain profiles. Participants in the Younger High Strain group were most likely to use home social care. All four groups were more likely to use home personal care in comparison to the Older Low Strain group. The Older Intermediate Strain, the Older High Strain and the Young Low Strain groups were more likely to use day care. Lastly, the people with dementia from all groups except for the Young Low Strain group were more likely to be of admitted when compared with the Older Low Strain group.

CarerQol, HADS depression and anxiety scores, perseverance time and relationship quality were subsequently added in a block to each of the logistic regressions to investigate whether these added value to the prediction (see Table 5). The p-value in Table 5 indicates the significance of the dummy set of the 5 caregiver profiles. For both home personal care and admission to hospital or care home, the predictors showed significant results, where the probability of using home personal care was higher for those caregivers with a lower quality of life and lower anxiety scores. A lower relationship quality as rated by the informal caregiver significantly predicted the use of day care, and the probability of admission to hospital or care home was higher for those with a lower perseverance time.

Table 6 shows the relationship between baseline care use and formal care use at either FU 1 or 2 . This was investigated with two independent variables: supportive services at baseline and non-personal service use at baseline (meals on wheels, domestic services, home social and day care without personal care). Non-personal service use at baseline significantly predicted the use of 2 out of 4 formal care types at FU1/2. Using supportive services at baseline significantly predicted the use of day care at FU1/2, but not home personal care or admission to hospital or care home.

\section{Discussion}

The challenge of understanding the factors that influence the take-up of formal care arises from the complex interplay between the characteristics of the services and of those using them. The latter may differ in relationship, disease severity, coping mechanisms, health problems amongst other factors (Neville, Beattie, Fielding, \& MacAndrew, 2015). By using caregiver profiles, we tried to encompass as many characteristics as possible in a simple typology, and have identified important differences in service use between these five types of caregiving contexts. 
Table 3. Service use distribution across caregiver profiles (\% ( $\mathrm{n})$ ) at baseline, and at FU1 (6 months) and/or FU2 (12 months).

\begin{tabular}{|c|c|c|c|c|c|c|}
\hline \multicolumn{7}{|l|}{ Baseline ( $n=451)$} \\
\hline & Home social & Home personal & Daycare & Admission & $\begin{array}{l}\text { Non-personal } \\
\text { services }\end{array}$ & $\begin{array}{l}\text { Supportive } \\
\text { services }\end{array}$ \\
\hline Older high strain & $5 \%(4)$ & $6 \%(5)$ & $16 \%(14)$ & 0 & $21 \%(30)$ & $23 \%(30)$ \\
\hline Younger high strain & $13 \%(8)$ & $11 \%(7)$ & $11 \%(7)$ & 0 & $16 \%(22)$ & $14 \%(18)$ \\
\hline Older low strain & $6 \%(6)$ & $4 \%(4)$ & $8 \%(8)$ & $<1 \%(1)$ & $12 \%(17)$ & $16 \%(20)$ \\
\hline Younger low strain & $11 \%(11)$ & $7 \%(7)$ & $20 \%(20)$ & 0 & $31 \%(44)$ & $14 \%(18)$ \\
\hline Older intermediate strain & $13 \%(12)$ & $3 \%(3)$ & $24 \%(23)$ & 0 & $19 \%(27)$ & $33 \%(43)$ \\
\hline \multicolumn{7}{|c|}{ Follow-up 1 and/or $2(n=370)$} \\
\hline & Home social & Home personal & Daycare & Admission & & \\
\hline Older high strain & $21 \%(14)$ & $26 \%(17)$ & $30 \%(20)$ & $21 \%(14)$ & & \\
\hline Younger high strain & $33 \%(14)$ & $28 \%(13)$ & $28 \%(12)$ & $23 \%(9)$ & & \\
\hline Older low strain & $10 \%(9)$ & $7 \%(6)$ & $15 \%(14)$ & $8 \%(7)$ & & \\
\hline Younger low strain & $16 \%(13)$ & $33 \%(28)$ & $39 \%(32)$ & $17 \%(15)$ & & \\
\hline Older intermediate strain & $22 \%(16)$ & $31 \%(23)$ & $38 \%(30)$ & $30 \%(22)$ & & \\
\hline
\end{tabular}

Percentages $(\mathrm{N}),{ }^{*}$ only used as baseline variables.

Table 4. Caregiver profiles as predictors for each of the 4 types of care use at FU1 (6 months) and/or FU2 (12 months).

\begin{tabular}{lllll}
\hline & Home social & Home personal & Day care & Admission \\
\hline Young low strain & $1.7(0.7-4.4)$ & $7.3(2.8-18.6)^{* *}$ & $3.7(1.8-7.5)^{* *}$ & $2.5(0.9-6.5)$ \\
Young high strain & $4.5(1.8-11.5)^{* *}$ & $5.7(2-16.3)^{* *}$ & $2.3(0.9-5.4)$ & $3.5(1.2-10.3)^{* *}$ \\
Old intermediate strain & $2.6(1.1-6.3)^{* *}$ & $6.4(2.5-16.8)^{* *}$ & $3.6(1.7-7.4)^{* *}$ & $3.1(2.1-13.1)^{* *}$ \\
Old high strain & $2.5(1-6.1)$ & $5.1(1.8-13.6)^{* *}$ & $5.2(1.2-5.6)^{* *}$ & $3.1(1.2-8.2)^{* *}$ \\
\hline \multicolumn{2}{l}{ Reference dummy: 'Old Low strain'. Odd's Ratio (lower Cl-upper Cl 95\%), **p-value $<0.05}$.
\end{tabular}

Table 5. Effects of CarerQol, HADS depression and anxiety scores, perseverance time and relationship quality on the relation between caregiver profiles and service use, in addition to caregiver profile at FU1 (6 months) and/or FU2 (12 months).

\begin{tabular}{lcccc}
\hline Caregiver profile & Home social & $\begin{array}{l}\text { Home personal } \\
* *\end{array}$ & $\begin{array}{l}\text { Day care } \\
* *\end{array}$ & $\begin{array}{l}\text { Admission } \\
* *\end{array}$ \\
\hline HADS-Anxiety & $1.0(0.9-1.1)$ & $0.9(0.8-1)^{* *}$ & $0.9(0.9-1)$ & $0.9(0.9-1.1)$ \\
HADS-Depression & $1.0(.865-1.1)$ & $0.9(.830-1.1)$ & $1(0.9-1.1)$ & $0.0(0.8-1)$ \\
Perseverance time & $0.9(0.7-1.3)$ & $0.8(0.6-1)$ & $1.1(0.8-1.4)$ & $0.6(0.4-0.8)^{* *}$ \\
PAI PWD-rated & $1.1(0.9-1.2)$ & $0.9(0.8-1)$ & $1(1-1.1)$ & $1(0.9-1.1)$ \\
PAI IC-rated & $0.9(0.9-1)$ & $1(0.9-1.1)$ & $0.9(0.9-1)^{* *}$ & $1(0.9-1.1)$ \\
CarerQol-sum & $1(0.9-1.2)$ & $0.9(0.7-1)^{* *}$ & $1(0.9-1.1)$ & $1(0.8-1.1)$ \\
\hline
\end{tabular}

Odd's Ratio (lower Cl-upper Cl 95\%). PWD: person with dementia IC: informal caregiver, HADS: Hospital Anxiety and Depression Scale PAl: positive affect index, $* * p$-value $<0.05$.

Table 6. Service use at baseline and supportive services at baseline predicting formal care use at FU1 (6 months) and/or FU2 (12 months).

\begin{tabular}{lcll}
\hline & Home personal care & Day care & Admission \\
\hline Non-personal service use at baseline & $4.9(2.9-8.4)^{* *}$ & $0.9(0.6-1.6)$ & $2.4(1.4-5.2)^{* *}$ \\
Supportive services & $1.5(0.9-2.6)$ & $2.5(1.6-4.1)^{* *}$ & $1.4(0.8-2.6)$ \\
\hline Odd's Ratio (lower Cl-upper Cl 95\%), ** $p$-value $<0.05$. & &
\end{tabular}

For home social care, the probability of using services is higher for the intermediate and high strain profiles compared to the low strain profiles. Participants in the Younger High Strain group were most likely to use home social care, such as companionship and social activities at home. This could be explained by the fact that the majority of young caregivers are often employed children with obligations towards their own families (Longacre, Valdmanis, Handorf, \& Fang, 2016). This also supports previous research, which indicated a higher amount of social care use by people with dementia who live alone (Kerpershoek et al., 2018). The use of home personal care, such as help at home with personal care, is much higher in all four groups compared to the reference (Older Low Strain) group. This could partly be explained by higher levels of objective and subjective burden, leading to increased needs regarding activities of daily living ( $A D L$ ). The finding that service use in the younger age profiles is so high could be due to living arrangement: children who are living apart from their parents are not able to provide continuous care. This supports previous research that found that those with dementia living alone are more likely to use meals on wheels and help at home with ADL (Schneider et al., 2002).

The Older Intermediate Strain and the Older High Strain group were more likely to use day care. This was also the case for the Young Low Strain group. Here caregivers were often employed children with less time to provide help with day-to-day activities. The fact that the Young High Strain group did not have a higher number of day care users could probably be explained by the relatively high number of admissions (to hospital or care home) in this group at follow-up. Lastly, people with dementia from all intermediate and high strain groups were more likely to be admitted in comparison to the low strain groups. The need for admission to hospital or care home may simply have been absent in these groups with a relatively low objective burden, which is supported by previous research (Afram et al., 2014; Gaugler, Yu, Krichbaum, \& Wyman, 2009; Wolfs et al., 2012).

The Older Intermediate Strain group has a distinctive profile in which the objective burden is the highest but the subjective burden is relatively low. These resilient 
caregivers seem to have found successful coping strategies. This supports previous reviews which have indicated that there is no association between dementia severity and subjective burden, since this relationship is more strongly influenced by coping styles and social support (Wolfs et al., 2012). The Older Intermediate Strain group also has the highest percentage of supportive service use at baseline, which could reflect a proactive attitude and active helpseeking. Overall, averaging across the different types of services at follow-up this group has the highest level of service use: a low subjective burden does not necessarily entail that no services are sought.

The two low strain groups have in common at baseline (Janssen et al., 2017) low levels of relative stress, higher levels of sense of coherence and a more internal locus of control, together with a higher proportion of care recipients with mild dementia and less neuropsychiatric symptoms. This profile, for both age groups, appears, over a 12month period, to be associated with less risk of admission to hospital or care home, and lower up-take of home social care. However, the older low strain group make less use of home personal care and day care. This may be attributed to the older caregivers being much more likely to be living with the person with dementia (100\% vs. $13.1 \%)$.

As the previously established caregiver profiles were shown to be associated with caregiver quality of life, depression, and perseverance time, we were interested in investigating whether these measures influence the relation between formal care use and being a certain type of caregiver. The probability of using home personal care was increased for those caregivers with lower anxiety scores and a lower quality of life. These results are difficult to interpret, and supportive literature is scarce. The probability of using day care was increased in those cases where the caregiver rated the relationship quality lower, which could be explained by the dyad wanting more time apart, or by tension in the home situation. This tension could arise if the couple is struggling to cope with the fact that the dementia is impacting not only both individuals, but also their relationship (Wadham, Simpson, Rust, \& Murray, 2016). In addition, when relationship quality is higher the caregiver might be better able to fulfil needs concerned with daytime activities themselves. Regarding admission admission to hospital or care home, results showed that a lower perseverance time adds to the prediction. It appears that caregivers' reports of their ability to carry on were a good indicator of what transpired.

Using low-intensity, less intrusive services at baseline (meals on wheels, domestic care, home social and day care without personal care) significantly predicted the use of home personal care and admission to hospital or care home at follow-up. From previous qualitative results of the Actifcare study (Kerpershoek et al., 2018) (Jelley et al., 2018), it was found that a gradual build up in care use is important to improve access to services. Starting with more accessible services such as domestic help or meals on wheels might lower the threshold to start using services involving personal care, and may help people with dementia to overcome reluctance to accept help from those outside the family. This was also reported in previous research (Gaugler, Kane, Kane, \& Newcomer, 2005) (Boots, Wolfs, Verhey, Kempen, \& de Vugt, 2015) suggesting that even though people with dementia and informal caregivers express reluctance, service use in the early stages can have favourable consequences.

In addition, the use of day care at follow-up was predicted by the use of supportive services (support groups, training session, individual/dyadic support, Alzheimer cafe). Information about available formal care is often provided as part of supportive services; for example, there is often contact with peers who share their experiences and knowledge. Given that a lack of knowledge has been reported as an important barrier in accessing formal care, these findings emphasize the need for information provision in the early stages of help-seeking (Brodaty et al., 2005; Stephan et al., 2018; Werner et al., 2014).

These analyses have some limitations. The trajectory over a one-year follow-up period may not be the same as that over a longer period of time. Although being on the verge of needing formal care services was an inclusion criterion, this was based on the expert opinion of a clinician and for various reasons, many dyads did not in fact take up additional services during the year. The service use variable is itself quite general, reflecting use at either followup point, and not taking into account differences in timing of the service uptake, the extent or intensity of service use, or any change in circumstances leading to it. Therefore, future studies could consider looking at characteristics and timing of service use into more detail. The caregiver profiles could be validated in other samples, perhaps with greater numbers of younger caregivers, given that only 2 clusters emerged for younger caregivers, compared with 3 for older caregivers. However, our results do help validate patterns of caregiving contexts that may have clinical utility.

\section{Conclusion}

The different established caregiver profiles (Janssen et al., 2017) have demonstrated their predictive value when examining dementia care use. The profiles include a broad range of information relating to the person with dementia and the informal caregiver, and therefore can provide useful information for professionals. These results suggest that some caregiver groups need more guidance in finding optimal access to formal care to ensure maintenance of independence in their home situation. Also, it seems important for clinicians to apply a more systemic approach, focusing on the relationship of the person with dementia and their spouse. In addition, the use of supportive and less intrusive, non-personal services in the early stages of dementia is recommended, as they could both provide information and lower the threshold to use more formal care in later stages. These findings could feed an intervention in which supportive services are introduced in an early stage, to investigate whether this indeed improves access to care.

\section{Ethical considerations}

The study protocol was approved by ethics committees in each of the 8 countries. The informal caregiver and the person with dementia both gave written informed consent. 


\section{Acknowledgments}

This is an EU Joint Programme - Neurodegenerative Disease Research (JPND) project. The project is supported through the following funding organizations under the aegis of JPND - www.jpnd.eu. Germany, Ministry of Education and Research, Ireland, Health research board, Italy, Ministry of Health, the Netherlands, The Netherlands organization for Health Research and Development, Sweden, The Swedish Research Council for Health, Working Life and Welfare, Norway, The Research Council of Norway, Portugal, Foundation for Science and Technology, United Kingdom, Economic and Social Research Council. The Actifcare Consortium partners are: Coordinator: Maastricht University (NL): Frans Verhey, professor (scientific coordinator, WP1 leader) Consortium members: Maastricht University (NL): Marjolein de Vugt, Claire Wolfs, Ron Handels, Liselot Kerpershoek. Martin-Luther University HalleWittenberg (DE): Gabriele Meyer (WP2 leader), Astrid Stephan, Anja Bieber, Anja Broda, Gabriele Bartoszek. Bangor University (UK): Bob Woods (WP3 leader), Hannah Jelley Nottingham University (UK): Martin Orrell, Karolinska Institutet (SE): Anders Wimo (WP4 leader), Anders Skoldunger, Britt-Marie Sjolund, Oslo University Hospital (NW): Knut Engedal, Geir Selbaek (WP5 leader), Mona Michelet, Janne Rosvik, Siren Eriksen. Dublin City University (IE): Kate Irving (WP6 leader), Louise Hopper, Rachael Joyce. CEDOC, Nova Medical School, Faculdade de Ciências Médicas, Universidade Nova de Lisboa (PT): Manuel Gonc, alves-Pereira, Maria J. Marques, M. Conceição Balsinha, Ana Machado, on behalf of the Portuguese Actifcare team. Alzheimer's Research Unit-Memory Clinic, IRCCS "Centro S.Giovanni di Dio (IT) Orazio Zanetti, Elisa Portolani

\section{Disclosure statement}

The authors report no conflicts of interest.

\section{Funding}

The project is supported through the following funding organizations under the aegis of JPND - www.jpnd.eu [grant number 733051001]. Germany, Ministry of Education and Research, Ireland, Health research board, Italy, Ministry of Health, the Netherlands, The Netherlands organization for Health Research and Development, Sweden, The Swedish Research Council for Health, Working Life and Welfare, Norway, The Research Council of Norway, Portugal, Foundation for Science and Technology (Fundação para a Ciência e Tecnologia [grant number FCT-JPND-HC/0001/2012], United Kingdom, Economic and Social Research Council. JPND has read and approved of the protocol of the Actifcare study.

\section{ORCID}

Ron Handels (ID http://orcid.org/0000-0002-8663-0630 Manuel Gonçalves-Pereira (D) http://orcid.org/0000-0003-1419-1306 Marjolein de Vugt (iD) http://orcid.org/0000-0002-2113-4134

\section{References}

Afram, B., Stephan, A., Verbeek, H., Bleijlevens, M. H. C., Suhonen, R., Sutcliffe, C., ... Hamers, J. P. H. (2014). Reasons for institutionalization of people with dementia: Informal caregiver reports from 8 European countries. Journal of the American Medical Directors Association, 15(2), 108-116. [CrossRef][10.1016/j.jamda.2013.09.012]

Antonovsky, A. (1993). The structure and properties of the sense of coherence scale. Social Science \& Medicine (1982), 36(6), 725-733.

Bengtson, V. L., \& Schrader, S. S. (1982). Parent-child relations. Research Instruments in Social Gerontology, 2, 115-186.

Bjelland, I., Dahl, A. A., Haug, T. T., \& Neckelmann, D. (2002). The validity of the Hospital Anxiety and Depression Scale: An updated literature review. Journal of Psychosomatic Research, 52(2), 69-77.

Boots, L. M., Wolfs, C. A., Verhey, F. R., Kempen, G. I., \& de Vugt, M. E. (2015). Qualitative study on needs and wishes of early-stage dementia caregivers: The paradox between needing and accepting help. International Psychogeriatrics, 27(6), 927-936.

Brodaty, H., Thomson, C., Thompson, C., \& Fine, M. (2005). Why caregivers of people with dementia and memory loss don't use services. International Journal of Geriatric Psychiatry, 20(6), 537-546.

Brouwer, W. B., van Exel, N. J., van Gorp, B., \& Redekop, W. K. (2006). The CarerQol instrument: A new instrument to measure care-related quality of life of informal caregivers for use in economic evaluations. Quality of Life Research, 15(6), 1005-1021.

Craig, A. R., Franklin, J. A., \& Andrews, G. (1984). A scale to measure locus of control of behaviour. British Journal of Medical Psychology, 57(2), 173-180.

Cummings, J. L., Mega, M., Gray, K., Rosenberg-Thompson, S., Carusi, D. A., \& Gornbein, J. (1994). The Neuropsychiatric Inventory: Comprehensive assessment of psychopathology in dementia. Neurology, 44(12), 2308-2314.

de Medeiros, K., Robert, P., Gauthier, S., Stella, F., Politis, A., Leoutsakos, J., ... Lyketsos, C. (2010). The Neuropsychiatric Inventory-Clinician rating scale (NPI-C): Reliability and validity of a revised assessment of neuropsychiatric symptoms in dementia. International Psychogeriatrics, 22(06), 984-994.

Eriksson, M., \& Lindström, B. (2005). Validity of Antonovsky's sense of coherence scale: A systematic review. Journal of Epidemiology \& Community Health, 59(6), 460-466.

Folstein, M. F., Folstein, S. E., \& McHugh, P. R. (1975). “Mini-mental state". A practical method for grading the cognitive state. Of Patients for the Clinician. Journal of Psychiatric Research, 12(3), 189-198.

Gaugler, J. E., Kane, R. L., Kane, R. A., \& Newcomer, R. (2005). Early community-based service utilization and its effects on institutionalization in dementia caregiving. The Gerontologist, 45(2), 177-185.

Gaugler, J. E., Yu, F., Krichbaum, K., \& Wyman, J. F. (2009). Predictors of nursing home admission for persons with dementia. Medical Care 47(2), 191-198.

Greene, J., Smith, R., Gardiner, M., \& Timbury, G. (1982). Measuring behavioural disturbance of elderly demented patients in the community and its effects on relatives: A factor analytic study. Age and Ageing, 11(2), 121-126.

Hoefman, R. J., van Exel, N. J. A., Foets, M., \& Brouwer, W. B. (2011) Sustained informal care: The feasibility, construct validity and test-retest reliability of the CarerQol-instrument to measure the impact of informal care in long-term care. Aging \& Mental Health, 15(8), 1018-1027.

Janssen, E. P., D., Vugt, M., Köhler, S., Wolfs, C., Kerpershoek, L., Handels, R. L., ...., Stephan, A. (2017). Caregiver profiles in dementia related to quality of life, depression and perseverance time in the European Actifcare study: The importance of social health. Aging \& Mental Health, 21(1), 49-57.

Jelley, H., Kerpershoek, L., Woods, B., Wolfs, C., D., Vugt, M., Bieber, A., ... Verhey, F. (2018). Carers experiences of timely access and use of dementia care services in 8 European countries.

Kerpershoek, L., D., Vugt, M., Wolfs, C., Jelley, H., Orrel, M., Woods, B., ...., Engedal, K. (2016). Access to timely formal dementia care in Europe: Protocol of the Actifcare (ACcess to Timely Formal Care) study. BMC Health Services Research, 16(1), 423.

Kerpershoek, L., D. V. M., Wolfs, C., Orrell, M., W. B., Jelley, H., Meyer, G., B. A., Stephan, A., ... Verhey, F. (2018). Is there equity in initial access to formal dementia care in Europe? The Andersen Model applied to the Actifcare cohort.

Kerpershoek, L., W. C., Verhey, F., J. H., Woods, B., B. A., Bartoszek G., Stephan, S., Selbaek, G., E. S., Sjölund, B., H. L., ... Zanetti, O., D. V. M. (2018). Optimizing access to formal dementia care: Qualitative findings from the European Actifcare study.

Litwin, H., \& Attias-Donfut, C. (2009). The inter-relationship between formal and informal care: A study in France and Israel. Ageing \& Society, 29(1), 71-91.

Longacre, M. L., Valdmanis, V. G., Handorf, E. A., \& Fang, C. Y. (2016). Work impact and emotional stress among informal caregivers for older adults. Journals of Gerontology Series B: Psychological Sciences and Social Sciences, 72(3), 522-531.

Morris, J. C. (1993). The Clinical Dementia Rating (CDR): Current version and scoring rules. Neurology, 43(11), 2412-2414.

Neville, C., Beattie, E., Fielding, E., \& MacAndrew, M. (2015). Literature review: Use of respite by careers of people with dementia. Health \& Social Care in the Community, 23(1), 51-63. 
Phillipson, L., Jones, S. C., \& Magee, C. (2014). A review of the factors associated with the non-use of respite services by careers of people with dementia: Implications for policy and practice. Health \& Social Care in the Community, 22(1), 1-12.

Quinn, C., Clare, L., \& Woods, B. (2009). The impact of the quality of relationship on the experiences and wellbeing of caregivers of people with dementia: A systematic review. Aging and Aging \& Mental Health, 13(2), 143-154.

Robinson, K., Buckwalter, K., \& Reed, D. (2005). Predictors of use of services among dementia caregivers. Western Journal of Nursing Research, 27(2), 126-140.

Schneider, J., Hallam, A., Murray, J., Foley, B., Atkin, L., Banerjee, S., ...., Mann, A. (2002). Formal and informal care for people with dementia: Factors associated with service receipt. Aging \& Mental Health, 6(3), 255-265.

Stephan, A., Bieber, A., Hopper, L., Joyce, R., Irving, K., Zanetti, O., ... Meyer, G. (2018). Barriers and facilitators to the access to formal dementia care: Findings of a focus group study with people with dementia, informal careers and health and social care professionals in eight European countries. BMC Geriatrics, 18(1), 131.

Stockwell-Smith, G., Kellett, U., \& Moyle, W. (2010). Why careers of frail older people are not using available respite services: An Australian study. Journal of Clinical Nursing, 19(13-14), 2057-2064

Toseland, R. W., McCallion, P., Gerber, T., \& Banks, S. (2002). Predictors of health and human services use by persons with dementia and their family caregivers. Social Science \& Medicine, 55(7), 1255-1266.

Ulstein, I., B., Wyller, T., \& Engedal, K. (2007). The relative stress scale: A useful instrument to identify various aspects of career burden in dementia? International Journal of Geriatric Psychiatry, 22(1), 61-67.
Vecchio, N., Fitzgerald, J. A., Radford, K., \& Fisher, R. (2016). The association between cognitive impairment and community service use patterns in older people living in Australia. Health \& Social Care in the Community, 24(3), 321-333.

Wadham, O., Simpson, J., Rust, J., \& Murray, C. (2016). Couples' shared experiences of dementia: A meta-synthesis of the impact upon relationships and couplehood. Aging \& Mental Health, 20(5), 463-473.

Weber, S. R., Pirraglia, P. A., \& Kunik, M. E. (2011). Use of services by community-dwelling patients with dementia: A systematic review. American Journal of Alzheimer's Disease \& Other Dementiasr, 26(3) 195-204.

Werner, P., Goldstein, D., Karpas, D. S., Chan, L., \& Lai, C. (2014). Helpseeking for dementia. A Systematic Review of the Literature. Alzheimer Disease \& Associated Disorders, 28(4), 299-310.

Wimo, A., Gustavsson, A., Jonsson, L., Winblad, B., Hsu, M. A., \& Gannon, B. (2012). Application of Resource Utilization in Dementia (RUD) instrument in a global setting. Alzheimer's \& Dementia: The Journal of the Alzheimer's Association, 9(4), 429-435. doi:10.1016/j. jalz.2012.06.008

Wimo, A., Jonsson, L., \& Zbrozek, A. (2010). The Resource Utilization in Dementia (RUD) instrument is valid for assessing informal care time in community-living patients with dementia. The Journal of Nutrition, Health \& Aging, 14(8), 685-690.

Wolfs, C. A., Kessels, A., Severens, J. L., Brouwer, W., de Vugt, M. E., Verhey, F. R., \& Dirksen, C. D. (2012). Predictive factors for the objective burden of informal care in people with dementia. a Systematic Review. Alzheimer Disease \& Associated Disorders, 26(3) 197-204.

Zigmond, A. S., \& Snaith, R. P. (1983). The hospital anxiety and depression scale. Acta Psychiatrica Scandinavica, 67(6), 361-370.

\section{Appendix}

\begin{tabular}{|c|c|c|c|c|c|}
\hline & \multicolumn{5}{|c|}{ Class } \\
\hline & 3 & 5 & 1 & 4 & 2 \\
\hline Label & Older low strain & Older intermediate strain & Older high strain & Younger low strain & Younger high strain \\
\hline Number caregivers (\%) & $106(23,4 \%)$ & $97(21.4 \%)$ & $88(19.4 \%)$ & $100(22.1)$ & $62(13.7)$ \\
\hline Age (SE) & $73.8(1.0)$ & $72.2(1.1)$ & $75.6(0.8)$ & $52.5(1.1)$ & $53.7(1.5)$ \\
\hline Female sex (\%) & $52.0(5.8)$ & $65.3(5.1)$ & $63.5(6.5)$ & $80.3(4.3)$ & $74.7(6.5)$ \\
\hline Living together (\%) & $100.0(0.0)$ & $95.0(2.6)$ & $100.0(0.0)$ & $13.1(5.0)$ & $46.4(8.4)$ \\
\hline Spouse/partner & $99.0(1.0)$ & $88.1(3.9)$ & $100.0(0.0)$ & $2.5(2.5)$ & $16.2(6.5)$ \\
\hline Time spent with PwD in hours/day (SE) & $2.9(0.4)$ & $15.1(0.4)$ & $4.9(0.5)$ & $1.6(2)$. & $3.3(0.5)$ \\
\hline Education years (SE) & $11.3(0.6)$ & $12.2(0.4)$ & $9.7(0.6)$ & $13.7(0.3)$ & $12.9(0.6)$ \\
\hline Paid work (\%) & $15.4(4.6)$ & $3.3(1.9)$ & $0.0(0.0)$ & $78.3(4.5)$ & $55.2(8.3)$ \\
\hline RSS (SE) & $13.1(1.0)$ & $26.7(1.1)$ & $28.2(1.4)$ & $13.11 .0)$ & $29.9(1.5)$ \\
\hline LOC (SE) & $44.6(1.1)$ & $50.1(1.2)$ & $56.5(1.0)$ & $40.6(1.0)$ & $53.2(1.3)$ \\
\hline SOC-13(SE) & $73.9(1.1)$ & $67.4(1.4)$ & $61.0(1.5)$ & $71.0(0.2)$ & $58.0(2.0)$ \\
\hline Moderate/severe dementia (\%) & $5.7(3.3 \%)$ & $38.9(5.5)$ & $19.0(5.1)$ & $10.5(3.6)$ & $32.6(8.2)$ \\
\hline \multicolumn{6}{|l|}{ Diagnosis } \\
\hline$A D(\%)$ & $52.0(5.7 \%$ & $47.4(5.5)$ & $45.4(6.7)$ & $47.3(5.5)$ & $49.6(7.3)$ \\
\hline $\operatorname{VaD}(\%)$ & $11.8(3.7 \%)$ & $13.8(3.8)$ & $13.3(4.2)$ & $11.0(3.2)$ & $6.1(3.6)$ \\
\hline Other/unknown (\%) & $4.2(2.4 \%)$ & $7.3(2.8)$ & $24.4(5.2)$ & $9.8(3.7)$ & $21.5(5.9)$ \\
\hline MMSE (SE) & $20.1(0.6)$ & $18.1(0.6)$ & $18.4(0.8)$ & $20.0(0.5)$ & $17.6(0.8)$ \\
\hline NPI (SE & $5.5(0.5)$ & $11.6(0.7)$ & $8.3(0.7)$ & $5.1(0.4)$ & $9.5(0.7)$ \\
\hline
\end{tabular}

SE: standard error; \%: percentage. RSS: Relative Stress Scale; LOC: Locus Of Control of behaviour; SOC-13: Sense Of Coherence scale-13; MMSE: Mini Mental State Examination of person with dementia; NPI: Neuropsychiatric Inventory of person with dementia Female sex: female sex of the caregiver; Moderate/severe dementia measured by use of the Clinical Dementia Rating scale of person with dementia; Diagnosis of person with dementia; AD: Alzheimer's disease; VaD: vascular dementia. 